\title{
Lateral retinacular release combined with MPFL reconstruction for patellofemoral instability: a systematic review
}

\author{
Filippo Migliorini $^{1}{ }^{10} \cdot$ Nicola Maffulli $^{2,3,4} \cdot$ Jörg Eschweiler $^{1} \cdot$ Valentin Quack $^{1} \cdot$ Markus Tingart $^{1} \cdot$ Arne Driessen $^{1}$
}

Received: 21 December 2019 / Accepted: 11 November 2020 / Published online: 14 December 2020

(c) The Author(s) 2020

\begin{abstract}
Introduction The role of the lateral retinaculum in patellofemoral instability is still debated. Lateral retinacular release (LRR), has been extensively performed in combination with different surgical procedures, including reconstruction of medio-patellofemoral ligament (MPFL). Despite controversial indications, the results from these studies seem promising. The present study conducts a systematic review about current biomechanical and clinical evidence concerning the role of LRR in combination with MPFL reconstruction. We performed a comprehensive literature research, comparing the outcomes of MPFL reconstruction with and without LRR.

Materials and methods This systematic review was conducted according to the PRISMA guidelines. The literature search was performed in August 2020. All articles describing the outcome of isolated MPFL reconstruction alone or in combination with a LRR in patients with recurrent patellofemoral instability were considered for inclusion. Only articles reporting data on patients with a minimum of 12-month follow-up were included. Only articles reporting quantitative data under the outcomes of interest were included.

Results A total of 63 articles were eligible for this systematic review, including 2131 knees. The mean follow-up was $40.87 \pm 24.1$ months. All scores of interests improved in favour of the combined group: Kujala $+3.8 \%(P=0.01)$, Lysholm $+4.2 \%(P=0.004)$, Tegner +0.8 points $(P=0.04)$, IKDC $+9.8 \%(P=0.02)$. The ROM was comparable between the two groups $(P=0.4)$. Similarity was found in terms of positivity to the apprehension test $(P=0.05)$, rate of complications $(P=0.1)$, re-dislocations $(P=0.8)$, and revision surgeries $(P=0.1)$.
\end{abstract}

Conclusion There is no evidence that adding a lateral release impacts positively on the outcome of MPFL reconstruction. Level of evidence: IV, Systematic review

Keywords Patellofermoral instability $\cdot$ Dislocations $\cdot$ MPFL reconstruction $\cdot$ Lateral retinacular release

\section{Introduction}

Filippo Migliorini

migliorini.md@gmail.com

1 Department of Orthopaedics, University Clinic Aachen, RWTH Aachen University Clinic, Pauwelsstraße 30, 52074 Aachen, Germany

2 Department of Medicine, Surgery and Dentistry, University of Salerno, Via S. Allende, 84081 Baronissi, SA, Italy

3 School of Pharmacy and Bioengineering, Keele University School of Medicine, Thornburrow Drive, Stoke on Trent, England

4 Barts and the London School of Medicine and Dentistry, Centre for Sports and Exercise Medicine, Queen Mary University of London, Mile End Hospital, 275 Bancroft Road, London E1 4DG, England
Patellofemoral instability is a complex disorder with higher prevalence in young and active individuals $[1,2]$. The aetiology of patellofemoral instability is multifactorial [3, 4]. Several risk factors have been described that synergistically contribute to joint instability [5, 6]. Most patients present a combination of two or more risk factors [7, 8]. Irrespective of the complexity of etiological causes, with the lateral dislocation of the patella, the syndrome becomes clinically apparent [8]. Several soft tissue and bony stabilizers are involved to ensure a physiological patellar tracking [9]. The bony anatomy of the patella and the trochlea is the most important static stabilizers [10]. Further dynamic restrains are the quadriceps and patellar tendon, the lateral retinaculum, and the medial patellofemoral ligament (MPFL) [9]. 
The MPFL is the most vital dynamic restrain to patellar lateralization during the first $30^{\circ}$ of flexion [11]. After the first event of patellar dislocation, the MPFL is practically always damaged [12]. MPFL reconstruction yields a high success in reducing the rate of further re-dislocations, restoring patients' quality of life and participation in recreational activities [13]. Conversely, the role of lateral retinaculum in patellofemoral instability remains unclear and debated $[14,15]$. Furthermore, lateral retinacular release (LRR) has been extensively performed in combination with various surgical interventions, including MPFL reconstruction [16-33]. Results from studies analysing results after MPFL reconstruction seem promising, but are also criticised for heterogeneity in indication and uncertain evidence [34, 35].

The present systematic review analyses current biomechanical and clinical evidence regarding the role of LRR in combination with MPFL reconstruction. The focus of the present study was on patient-reported outcome measures (PROMs), clinical examination, and complications.

\section{Materials and methods}

\section{Search strategy}

This systematic review was conducted in accordance with the Preferred Reporting Items for Systematic Reviews and Meta-Analyses (PRISMA) [36]. The PICO algorithm guided the initial search:

- P (population): patellofemoral instability;

- I (intervention): isolated MPFL reconstruction;

- C (comparison): combined MPFL reconstruction with LRR;

- O (outcomes): PROMs, clinical examination, complications.

\section{Literature search}

Two authors (JE, FM) independently performed the literature search accessing the following databases Pubmed, Google Scholar, Embase, Scopus in August 2020. The following keywords were used for the search: patellofemoral instability, recurrent, dislocations, luxation combined with MPFL reconstruction, lateral retinacula, lateral release, redislocation, Kujala, Lyshom. If title matched the topic, the abstract was read and the full text of the article was accessed. The bibliographies of the articles of interest were screened by hand. Disagreements between the author were debated and mutually solved.

\section{Eligibility criteria}

All articles about treatment of patellofemoral instability with an isolated MPFL reconstruction or in combination with lateral retinacula release were considered for inclusion. Articles' level of evidence I to IV, according to the Oxford Centre of Evidenced-Based Medicine [37], was included in the present work. Given the authors' language capabilities, articles in English, Italian, French, Spanish, and German were considered for inclusion. Only studies investigating patients affected by recurrent dislocations were eligible. Articles reporting treatment in patients with acute, congenital or habitual dislocations were excluded. Articles about the treatment of patellofemoral instability after total knee arthroplasty were excluded. Techniques, comments, letters, editorials, protocols, and guidelines were excluded. Biomechanical, animal, and cadaveric studies were also excluded. Articles reporting a followup $<12$ months were excluded. Articles reporting patellofemoral outcomes in revision setting were excluded. Articles combining MPFL reconstruction with bony procedures (trochleoplasty, Elmslie Trillat, Maquet, Fulkerson, Roux-Goldthwait, rotational osteotomies) were excluded. Articles combining MPFL reconstruction with other soft tissue procedures rather than the LRR (medial retinacular plication, ligament plasties, MPFL suture, muscle advancements, or tendon transfer) were excluded. Only articles reporting quantitative data under the outcomes of interest were included. Disagreements between the authors were debated and solved by a third author (MT).

\section{Outcomes of interest}

The following data were collected: generalities (author, year, type of study), demographic baseline (number of samples, mean age), mean follow-up, presence of previous intervention, presence of patho-anatomical risk factors (patella alta, elevated TT-TG, trochlear dysplasia), type of graft, and fixation. The following outcomes of interest were collected: Kujala Anterior Knee Pain Scale [28], Lysholm Knee Scoring Scale [29], Tegner Activity Scale [38], IKDC [39], range of motion (ROM). The same authors also collected clinical examinations, complications, revisions and re-dislocations.

\section{Methodological quality assessment}

For the methodological quality assessment, we referred to the PEDro score. Two authors (FM, JE) independently scored each included article. This score analyzed each article included using the following criteria: clear eligibility 
criteria, allocation, randomization and blinding methods, follow-up duration, analysis of variables, and intention to treat. The final scoring resulted in a value ranking from 0 (poor quality) to 10 (excellent quality).

\section{Statistical analysis}

Statistical analysis was performed using the IBM SPSS Software version 25 . For continuous variables, the mean difference (MD) effect measure standard deviation and T-test were evaluated. For binary data, the odd ratio (OR) effect measure was performed, with confidence interval (CI) set at $95 \%$ and chi-quare test. Values of $\mathrm{P}<0.05$ were considered statistically significant.

\section{Results}

\section{Search result}

The initial literature search resulted in 966 articles, of which 274 were excluded because of redundancy. Another 415 articles were excluded because they did not match the eligibility criteria; a further 203 articles did not report quantitative data under the endpoints of interest. An additional 11 publications were rejected because they reported uncertain data. Thus, a total of 63 articles were eligible for this systematic review: 24 reporting about MPFL reconstruction in combination with LRR and 40 reporting about isolated MPFL reconstruction. The flow chart of the literature search is shown in Fig. 1.
Fig. 1 PRISMA flow chart of the literature search
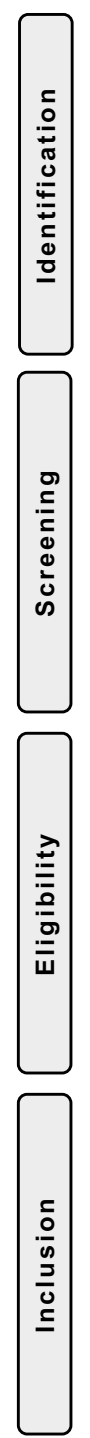

Articles identified through the database search $(n=966)$

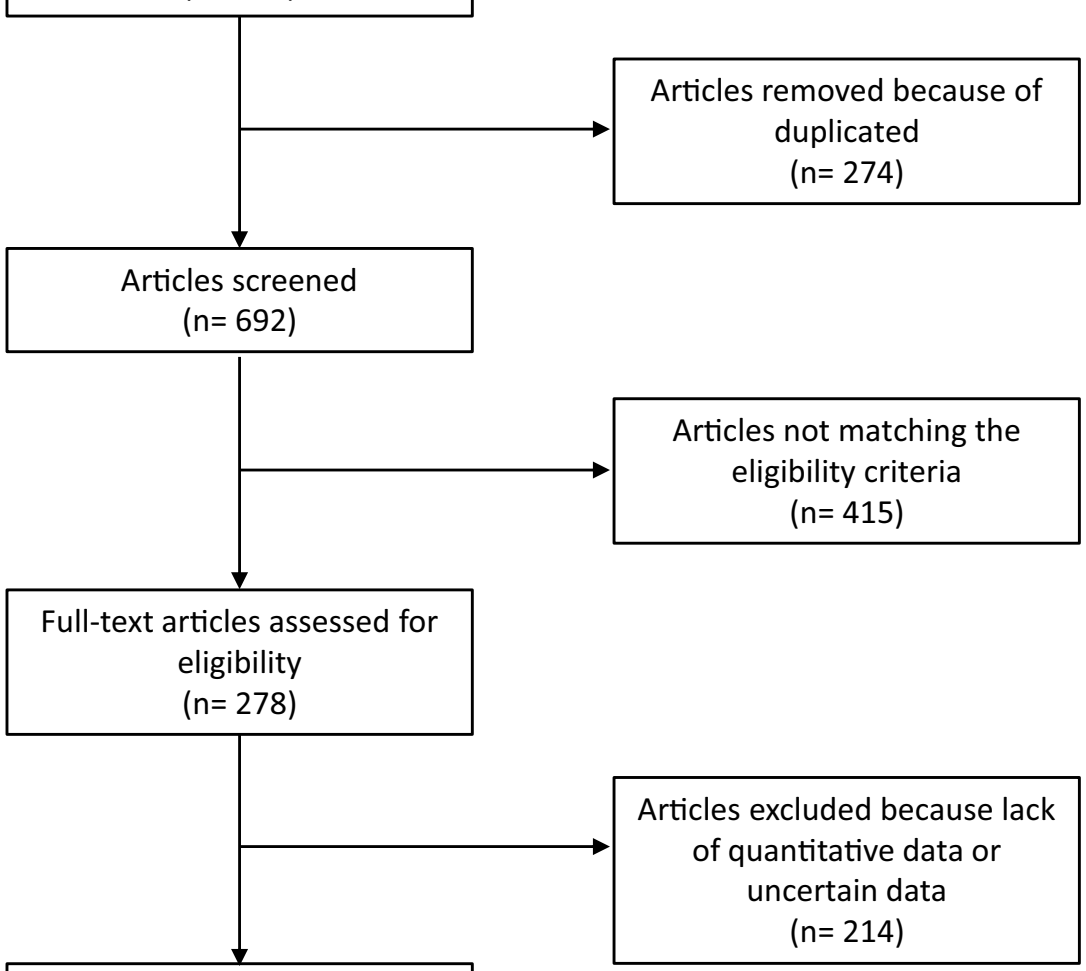

Articles included in quantitative synthesis $(n=64)$ 


\section{Methodological quality assessment}

The PEDro score evidenced some limitations of the methodological quality assessment: the overall lack of randomization and blinding methods. Points of strength are represented by the good analysis, along with the adequate duration of the follow-up, both performed by most of the included papers. Concluding, the overall quality assessment was good, scoring 6.7 points. The PEDro score related to each study is shown in Tables 1 and 2.

\section{Patient demographic}

Data from a total of 2131 procedures were collected. The mean follow-up was $40.87 \pm 24.1$ months. In the combined group, a total of 585 patients with a mean age of
Table 1 Demographic baseline of studies included concerning the isolated MPFL reconstruction and related PEDro score

\begin{tabular}{|c|c|c|c|c|c|}
\hline Author, year & Study design & PEDro score & Knees $(n)$ & Mean age & $\begin{array}{l}\text { Follow-up } \\
\text { (months) }\end{array}$ \\
\hline Amin et al. 2015 [64] & & & & & 24.0 \\
\hline Astur et al. 2015 [65] & Prospective & 8 & 30 & 31.1 & 60.0 \\
\hline Astur et al. 2015 [65] & Prospective & 8 & 28 & 28.3 & 60.0 \\
\hline Ballal et al. 2018 [66] & Prospective & 7 & 20 & 24.4 & 12.0 \\
\hline Biondi Pinheiro et al. 2018 [67] & Retrospective & 7 & 16 & 27.1 & 31.2 \\
\hline Biondi Pinheiro et al. 2018 [67] & Retrospective & 7 & 21 & 26.4 & 34.8 \\
\hline Bitar et al. 2011 [68] & Prospective & 8 & 21 & NR & 24.0 \\
\hline Bitar et al. 2012 [69] & Prospective & 7 & 56 & 23.0 & 19.3 \\
\hline Calapodopulos et al. 2016 [70] & Prospective & 5 & 22 & 23.1 & 30.0 \\
\hline Christiansen et al. 2008 [71] & Prospective & 6 & 32 & 22.0 & 22.0 \\
\hline Csintalan et al. 2013 [72] & Retrospective & 5 & 56 & 4.3 & 51.0 \\
\hline Deie et al. 2011 [73] & Retrospective & 5 & 31 & 22.2 & 39.0 \\
\hline Feller et al. 2014 [74] & Retrospective & 5 & 26 & 24.4 & 42.0 \\
\hline Fink et al. 2014 [75] & Prospective & 7 & 17 & 21.5 & 12.0 \\
\hline Gomes et al. 1992 [76] & Retrospective & 5 & 30 & 28.0 & 39.0 \\
\hline Gomes et al. 2004 [77] & Prospective & 6 & 16 & 26.7 & 60.0 \\
\hline Gomes et al. 2008 [78] & Prospective & 7 & 12 & 19.3 & 53.0 \\
\hline Gomes et al. 2008 [78] & Prospective & 7 & 12 & 19.0 & 53.0 \\
\hline Goncaives et al. 2015 [79] & Prospective & 6 & 22 & 28.6 & 26.2 \\
\hline Goyal et al. 2013 [80] & Retrospective & 5 & 32 & 25.0 & 38.0 \\
\hline Hiemstra et al. 2017 [81] & Retrospective & 5 & 155 & 25.4 & 24.4 \\
\hline Hinterwimmer et al. 2013 [82] & Retrospective & 6 & 19 & 23.0 & 16.0 \\
\hline Howells et al. 2012 [83] & Prospective & 7 & 155 & 26.0 & 16.0 \\
\hline Kang et al. 2013 [84] & Prospective & 8 & 82 & 28.8 & 24.0 \\
\hline Kim et al. 2015 [85] & Retrospective & 6 & 9 & 24.6 & 19.3 \\
\hline Kita et al. 2015 [86] & Prospective & 7 & 44 & 25.4 & 39.0 \\
\hline Krishna Kumar et al. 2014 [87] & Prospective & 7 & 30 & 18.0 & 25.0 \\
\hline Lind et al. 2016 [88] & Prospective & 8 & 24 & 12.5 & 39.0 \\
\hline Lind et al. 2016 [88] & Prospective & 8 & 179 & 23.0 & 41.0 \\
\hline Lippacher et al. 2014 [13] & Retrospective & 7 & 68 & 18.3 & 24.7 \\
\hline Malatray et al. 2019 [53] & Prospective & 9 & 16 & 28.0 & 24.0 \\
\hline Niu et al. 2017 [89] & Prospective & 7 & 30 & 25.0 & 55.1 \\
\hline Panni et al. 2011 [90] & Retrospective & 5 & 48 & 0.3 & 33.0 \\
\hline Ronga et al. 2009 [91] & Prospective & 5 & 37 & 28.0 & 37.0 \\
\hline Sadigursky et al. 2016 [92] & Prospective & 7 & 31 & 29.4 & 12.0 \\
\hline Slenker et al. 2013 [93] & Retrospective & 6 & 35 & 20.6 & 21.0 \\
\hline Sillanpaa et al. 2008 [94] & Retrospective & 6 & 18 & 20.2 & 121.2 \\
\hline Smith et al. 2014 [95] & Retrospective & 6 & 21 & 23.0 & 12.0 \\
\hline Thaunat et al. 2007 [96] & Retrospective & 5 & 23 & 22.0 & 28.0 \\
\hline Wagner et al. 2013 [7] & Prospective & 6 & 50 & 19.0 & 12.0 \\
\hline
\end{tabular}


Table 2 Demographic baseline of studies included concerning the MPFL reconstruction in combination with LRR and related PEDro score

\begin{tabular}{llllll}
\hline Author, year & Study design & PEDro score & Knees $(n)$ & Mean age & $\begin{array}{l}\text { Follow- } \\
\text { up } \\
\text { (months) }\end{array}$ \\
& & & & & 31.0 \\
Ahmad et al. 2009 [17] & Retrospective & 5 & 20 & 23.0 & 68.4 \\
Han et al. 2011 [18] & Retrospective & 6 & 59 & 24.3 & 27.8 \\
Kumahashi et al. 2012 [97] & Prospective & 6 & 5 & 13.6 & 45.0 \\
Kumahashi et al. 2016 [98] & Prospective & 7 & 17 & 22.0 & 78.5 \\
Li et al. 2014 [19] & Prospective & 7 & 65 & 29.4 & 35.0 \\
Lin et al. 2015 [20] & Retrospective & 5 & 18 & NR \\
Ma et al. 2013 [21] & Prospective & 8 & 32 & 28.4 & 40.0 \\
Malatray et al. 2019 [53] & Prospective & 9 & 17 & 28.0 & 24.0 \\
Matsushita et al. 2014 [56] & Retrospective & 6 & 21 & 22.1 & 44.0 \\
Matsushita et al. 2014 [56] & Retrospective & 6 & 18 & 23.5 & 38.0 \\
Nomura et al. 2000 [55] & Prospective & 7 & 27 & 21.0 & 70.8 \\
Nomura et al. 2006 [22] & Retrospective & 6 & 12 & 24.8 & 51.0 \\
Nomura et al. 2007 [23] & Retrospective & 5 & 24 & 22.5 & 142.8 \\
Raghuveer et al. 2012 [24] & Prospective & 7 & 15 & 29.2 & 42.0 \\
Rhatomy et al. 2019 [99] & Retrospective & 7 & 8 & 20.0 & 24.0 \\
Suganuma et al. 2016 [25] & Retrospective & 6 & 18 & 20.7 & 51.6 \\
Suganuma et al. 2016 [25] & Retrospective & 6 & 28 & 20.3 & 48.0 \\
Vavalle et al. 2016 [100] & Retrospective & 5 & 16 & 22.0 & 38.0 \\
Wang et al. 2010 [101] & Retrospective & 7 & 28 & 29.0 & 42.0 \\
Wang et al. 2016 [33] & Retrospective & 6 & 26 & 26.3 & 38.2 \\
Wantabe et al. 2008 [57] & Retrospective & 7 & 19.0 & 51.6 \\
Witonski et al. 2013 [102] & Prospective & 7 & 27.2 & 43.0 \\
Zhang et al. 2019 [54] & Prospective & 7 & 21.0 & 96.0 \\
\hline & & 60 & & \\
\hline
\end{tabular}

$23.4 \pm 4.1$ years were included. In the isolated group, a total of 1599 knees with a mean age of $22.1 \pm 6.2$ years were included. No significant discrepancies were denoted concerning the age at baseline $(P=0.2)$. Table 1 and 2 show the demographic baseline data of the study groups.

\section{Outcomes of interest}

All PROMs of interests improved in favour of the combined group: Kujala (MD 3.8; $P=0.01$ ), Lysholm (MD 4.2; $P=0.004)$, Tegner (MD 0.8; $P=0.04$ ), IKDC MD 9.8; $P=0.02)$. The ROM resulted comparable among the groups $(P=0.4)$. The main results of the PROMs and ROM at last follow-up are shown in detail in Table 3.
Between the two groups, similarity was found in terms of positivity to the apprehension test (OR 1.8; 95\% CI: 0.9-3.1; $P=0.05$ ), rate of complications (OR 1.1; 95\% CI: 0.7-1.7; $P=0.1$ ), re-dislocations (OR 0.3 ; 95\% CI: $0.1-1.0 ; P=0.8$ ) and revision surgeries (OR 0.5; 95\% CI: $0.3-1.1 ; P=0.1$ ).

\section{Discussion}

According to the main findings of the present systematic review, MPFL reconstruction combined with LRR reported greater Kujala, Lysholm, and Tegner scores compared to the isolated procedure. However, the improvements of these aforementioned PROMs did not reach the
Table 3 Mean values of the PROMs and ROM at last follow-up

\begin{tabular}{lccccccc}
\hline \multirow{2}{*}{ Endpoint } & \multicolumn{2}{l}{ Isolated group } & & \multicolumn{2}{l}{ Combined group } & MD & \multirow{2}{*}{$P$} \\
\cline { 2 - 3 } & Mean \pm SD & $95 \%$ CI & & Mean \pm SD & $95 \%$ CI & & \\
\hline Kujala & $86.9 \pm 6.1$ & $84.94-88.76$ & & $90.7 \pm 5.3$ & $88.38-93.02$ & 3.8 & 0.01 \\
Lysholm & $88.1 \pm 4.9$ & $86.79-89.35$ & & $92.3 \pm 2.7$ & $91.15-93.49$ & 4.2 & 0.004 \\
Tegner & $4.9 \pm 0.7$ & $4.71-5.13$ & & $5.7 \pm 1.1$ & $5.16-6.16$ & 0.8 & 0.04 \\
IKDC & $75.7 \pm 4.7$ & $74.19-77.17$ & & $85.5 \pm 5.1$ & $83.25-87.69$ & 9.8 & 0.02 \\
ROM & $134.7 \pm 10.1$ & $131.28-138.02$ & & $133.8 \pm 7.9$ & $130.39-137.27$ & -0.9 & 0.4 \\
\hline
\end{tabular}


minimal clinically important difference (MCID), and thus their clinical relevance is questionable [38, 40-42]. The rate of overall complications, positivity to the apprehension test, revision surgeries, and re-dislocations were comparable among the two cohort, as well as the range of motion of the knee.

LRR was widely undertaken for a relatively long period. Merchant and Mercer in 1974 published their results on LRR in 16 patients suffering from recurrent subluxations or dislocations, reporting satisfying results in patients with chondromalacia and malalignment [30]. LRR became standard surgery for patellofemoral instability and anterior knee pain, yielding satisfying results [43-47]. At present, however, these indications are outdated, and in the past 15 years, the role of isolated LRR has been revised extensively. At present, the indication for isolated LRR remains imbalance of the extensor mechanism during contraction of the quadriceps muscle group, when excessive tension of the lateral retinaculum exists. Patients suffering from anterior knee pain from lateral hyperpressure syndrome (LHPS) with evidence of patellar tilt are suitable for an isolated LRR [14, 34, 48, 49]. Herein, we remarked the role of the lateral retinaculum lengthening (LRL) [50]. In patients with LHPS, LRL produces less medial instability and quadriceps atrophy with better clinical outcomes at 24 months compared with LRR [51].

In comparison with normal intact knees, an isolated LRR will reduce the forces required to displace the patella $10 \mathrm{~mm}$ laterally approximately by $10-20 \%$ within the range from $0^{\circ}$ to $30^{\circ}$ flexion $[26,27]$. Furthermore, a LRR will probably recentralize the patella on its physiological axis. At the same time, however, LRR increases patellar instability by decreasing the pressure in the lateral patellar compartment. Thus, LRR reduces the ability of dynamic stabilizers to maintain patellar tracking and increase role of the anatomical factors that predisposed the patellar to the first dislocation. Therefore, even if patellar tracking may be centralized following LRR, the tendency to lateralization is increased.

The role of combination of MPFL reconstruction and LRR is not entirely clarified. The MPFL is nearly always damaged after the first dislocation, leading to joint instability and a tendency of patella lateralization. Combining LRR with MPFL reconstruction is controversial, and the indications have not been entirely clarified.

Regarding the studies included in the combined group, we must accentuate that few authors performed a LRR in all of their patients [18, 21, 52, 53]. Lateral release has been performed with heterogeneous criteria, and the surgical indications are controversial. Han et al. [18] combined routinely a LRR because they hypothesize that this will improve the post-operative ROM. LRR was performed when lateral retinaculum over-tension (defined as force directed medially being less than one fourth of the force directed laterally) was noticed [32]. Other authors performed an LRR in patients with moderate patellar maltracking or excessive tightness or stiffness of the soft tissue structures lateral to the patella [22-25, 32, 33, 54-57]; however, quantification of these variables has not been undertaken. Other authors $[17,19,20]$ evaluated the stability of the lateral structures by everting the patella: if unable to evert the patella, a LRR was performed. Regardless of the criteria used to indicate a LRR, its role in the management of patellar instability is still unclear and debated. We hypothesize that the reduced lateral compression within the articular surface explain the better results observed in the LRR group. In fact, the lateral patellar facet slides over the lateral trochlea and subsequently over the lateral femoral condyle: in patellar dislocation, the trauma causes chondral and osteochondral defects in $50-96 \%$ of cases, especially after the first dislocation [58-63].

The present study has several limitations. First, the studies performing isolated MPFL reconstruction were far more numerous than those performing a combined intervention. Another important limitation is the overall low quality of studies included. To improve data pooling, both prospective and retrospective studies were included in the analysis, representing another potential limitation of the present study. Further studies should improve the evidence on this topic, improving the quality of their methodology. Further studies should also clarify the role of lateral retinaculum lengthening. The analyses were performed regardless to the type of graft (e.g. semitendinosus, gracilis, quadriceps), the number of bundle (single or double), and the presence of additional risk factors (e.g. patella alta, elevated TT-TG distance, genu valgum) that may influence the surgical outcomes. Given these limitations, data must be interpreted with caution. Strengths of the present work were the comprehensive nature of the literature search, along with the strict eligibility criteria and the adequate baseline comparability. To the best of our knowledge, this investigation involves the highest number of studies and procedures, thus representing another important point of strength. Given the lack of evidence and heterogeneous indications, future studies should investigate which cohort of patients can benefit from a LRR.

\section{Conclusion}

According to the main results of this systematic review, there is no evidence of a clinically relevant difference between the two procedures. On this basis, isolated MPFL reconstruction should be recommended. There is no evidence that adding a lateral release impacts positively on the outcome of MPFL reconstruction. The role of lateral retinacular lengthening should be studied more extensively. 
Funding Open Access funding enabled and organized by Projekt DEAL.

\section{Compliance with ethical standards}

Conflict of interest The authors declare that they have no conflict of interest.

Ethical approval This article does not contain any studies with human participants or animals performed by any of the authors.

Informed consent For this type of study informed consent is not required.

Open Access This article is licensed under a Creative Commons Attribution 4.0 International License, which permits use, sharing, adaptation, distribution and reproduction in any medium or format, as long as you give appropriate credit to the original author(s) and the source, provide a link to the Creative Commons licence, and indicate if changes were made. The images or other third party material in this article are included in the article's Creative Commons licence, unless indicated otherwise in a credit line to the material. If material is not included in the article's Creative Commons licence and your intended use is not permitted by statutory regulation or exceeds the permitted use, you will need to obtain permission directly from the copyright holder. To view a copy of this licence, visit http://creativecommons.org/licenses/by/4.0/.

\section{References}

1. Migliorini F, Driessen A, Quack V, Schenker H, Tingart M, Eschweiler J (2020) Patellar fixation graft via suture anchors versus tunnel techniques during isolated MPFL reconstruction for recurrent patellofemoral instability: a systematic review of the literature. Arch Orthop Trauma Surg. https://doi.org/10.1007/ s00402-020-03420-8

2. Migliorini F, Trivellas A, Driessen A, Quack V, Tingart M, Eschweiler J (2020) Graft choice for isolated MPFL reconstruction: gracilis versus semitendinosus. Eur J Orthop Surg Traumatol. https://doi.org/10.1007/s00590-020-02636-z

3. Migliorini F, Rath B, Tingart M, Meisen N, Eschweiler J (2019) Surgical management for recurrent patellar dislocations in skeletally immature patients. Eur J Orthop Surg Traumatol. https:// doi.org/10.1007/s00590-019-02483-7

4. Migliorini F, Rath B, Tingart M, Niewiera M, Eschweiler J (2019a) Distal alignment procedures for patellofemoral instability: comprehensive review of the literature. Eur J Orthop Surg Traumatol 29(7):1579-1588. https://doi.org/10.1007/s0059 0-019-02451-1

5. Boling MC, Padua DA, Marshall SW, Guskiewicz K, Pyne S, Beutler A (2009) A prospective investigation of biomechanical risk factors for patellofemoral pain syndrome: the Joint Undertaking to Monitor and Prevent ACL Injury (JUMP-ACL) cohort. Am J Sports Med 37(11):2108-2116. https://doi.org/10.1177/03635 46509337934

6. Hiemstra LA, Kerslake S, Lafave M (2017a) Assessment of demographic and pathoanatomic risk factors in recurrent patellofemoral instability. Knee Surg Sports Traumatol Arthrosc 25(12):3849-3855. https://doi.org/10.1007/s00167-016-4346-0

7. Wagner D, Pfalzer F, Hingelbaum S, Huth J, Mauch F, Bauer $G$ (2013) The influence of risk factors on clinical outcomes following anatomical medial patellofemoral ligament (MPFL) reconstruction using the gracilis tendon. Knee Surg Sports Traumatol Arthrosc 21(2):318-324. https://doi.org/10.1007/s0016 7-012-2015-5

8. Migliorini F, Rath B, Tingart M, Niewiera M, Eschweiler J (2019b) Distal alignment procedures for patellofemoral instability: comprehensive review of the literature. Eur J Orthop Surg Traumatol. https://doi.org/10.1007/s00590-019-02451-1

9. Ferrua P, Kruckeberg BM, Pasqualotto S, Berruto M, Randelli P, Arendt EA (2019) Proximal medial patellar restraints and their surgical reconstruction. J Orthop Traumatol 20(1):17. https://doi. org/10.1186/s10195-019-0525-3

10. Laidlaw MS, Diduch DR (2017) Current concepts in the management of patellar instability. Indian J Orthop 51(5):493-504. https ://doi.org/10.4103/ortho.IJOrtho_164_17

11. Buchanan G, Torres L, Czarkowski B, Giangarra CE (2016) Current concepts in the treatment of gross patellofemoral instability. Int J Sports Phys Ther 11(6):867-876

12. Nomura E (1999) Classification of lesions of the medial patello-femoral ligament in patellar dislocation. Int Orthop 23(5):260-263

13. Lippacher S, Dreyhaupt J, Williams SR, Reichel H, Nelitz M (2014) Reconstruction of the medial patellofemoral ligament: clinical outcomes and return to sports. Am J Sports Med 42(7):1661-1668. https://doi.org/10.1177/0363546514529640

14. Fithian DC, Paxton EW, Post WR, Panni AS, International Patellofemoral Study G (2004) Lateral retinacular release: a survey of the International Patellofemoral Study Group. Arthroscopy 20(5):463-468. https://doi.org/10.1016/j.arthr o.2004.03.002

15. Fonseca L, Kawatake EH, Pochini AC (2017) Lateral patellar retinacular release: changes over the last ten years. Rev Bras Ortop 52(4):442-449. https://doi.org/10.1016/j.rboe.2017.06.003

16. Gerbino PG (2015) Lateral retinacular release and reconstruction. Ann Transl Med 3(Suppl 1):S42. https://doi.org/10.3978/j. issn.2305-5839.2015.03.48

17. Ahmad CS, Brown GD, Shubin Stein BE (2009) The docking technique for medial patellofemoral ligament reconstruction: surgical technique and clinical outcome. Am J Sports Med 37(10):2021-2027. https://doi.org/10.1177/0363546509336261

18. Han H, Xia Y, Yun X, Wu M (2011) Anatomical transverse patella double tunnel reconstruction of medial patellofemoral ligament with a hamstring tendon autograft for recurrent patellar dislocation. Arch Orthop Trauma Surg 131(3):343-351. https:// doi.org/10.1007/s00402-010-1173-5

19. Li J, Li Y, Wei J, Wang J, Gao S, Shen Y (2014) A simple technique for reconstruction of medial patellofemoral ligament with bone-fascia tunnel fixation at the medial margin of the patella: a 6-year-minimum follow-up study. J Orthop Surg Res 9:66. https ://doi.org/10.1186/s13018-014-0066-7

20. Lin KY, Lu YC, Renn JH (2015) The double-pulley technique for anatomical double-bundled medial patellofemoral ligament reconstruction. Injury 46(8):1619-1624. https://doi. org/10.1016/j.injury.2015.04.017

21. Ma LF, Wang F, Chen BC, Wang CH, Zhou JW, Wang HY (2013) Medial retinaculum plasty versus medial patellofemoral ligament reconstruction for recurrent patellar instability in adults: a randomized controlled trial. Arthroscopy 29(5):891-897. https ://doi.org/10.1016/j.arthro.2013.01.030

22. Nomura E, Inoue M (2006) Hybrid medial patellofemoral ligament reconstruction using the semitendinous tendon for recurrent patellar dislocation: minimum 3 years' follow-up. Arthroscopy 22(7):787-793. https://doi.org/10.1016/j.arthro.2006.04.078

23. Nomura E, Inoue M, Kobayashi S (2007) Long-term followup and knee osteoarthritis change after medial patellofemoral ligament reconstruction for recurrent patellar dislocation. Am 
J Sports Med 35(11):1851-1858. https://doi.org/10.1177/03635 46507306161

24. Raghuveer RK, Mishra CB (2012) Reconstruction of medial patellofemoral ligament for chronic patellar instability. Indian J Orthop 46(4):447-454. https://doi.org/10.4103/0019-5413.97259

25. Suganuma J, Mochizuki R, Sugiki T, Inoue Y, Kitamura K, Akutsu S, Ono H (2016) Reconstruction of the medial patellofemoral ligament using a synthetic graft with arthroscopic control of patellofemoral congruence. Arthroscopy 32(11):22592268. https://doi.org/10.1016/j.arthro.2016.02.004

26. Christoforakis J, Bull AM, Strachan RK, Shymkiw R, Senavongse W, Amis AA (2006) Effects of lateral retinacular release on the lateral stability of the patella. Knee Surg Sports Traumatol Arthrosc 14(3):273-277. https://doi.org/10.1007/s0016 7-005-0699-5

27. Desio SM, Burks RT, Bachus KN (1998) Soft tissue restraints to lateral patellar translation in the human knee. Am J Sports Med 26(1):59-65. https://doi.org/10.1177/03635465980260012701

28. Kujala UM, Jaakkola LH, Koskinen SK, Taimela S, Hurme M, Nelimarkka O (1993) Scoring of patellofemoral disorders. Arthroscopy 9(2):159-163

29. Lysholm J, Gillquist J (1982) Evaluation of knee ligament surgery results with special emphasis on use of a scoring scale. Am J Sports Med 10(3):150-154. https://doi.org/10.1177/03635 4658201000306

30. Merchant AC, Mercer RL (1974) Lateral release of the patella. A preliminary report. Clin Orthop Relat Res 103:40-45. https:// doi.org/10.1097/00003086-197409000-00027

31. Sillanpaa P, Mattila VM, Iivonen T, Visuri T, Pihlajamaki H (2008) Incidence and risk factors of acute traumatic primary patellar dislocation. Med Sci Sports Exerc 40(4):606-611. https ://doi.org/10.1249/MSS.0b013e318160740f

32. Wang FKH, Chen B, Chen W, Su Y, Zhang Y (2010) Combination of medial patellofemoral ligament reconstruction with vastus medialis advancement for chronic patellar dislocation. Chin Med J 123:3024-3029

33. Wang HD, Dong JT, Gao SJ (2016) Medial patellofemoral ligament reconstruction using a bone groove and a suture anchor at patellar: a safe and firm fixation technique and 3-year followup study. J Orthop Surg Res 11(1):138. https://doi.org/10.1186/ s13018-016-0473-z

34. Clifton R, Ng CY, Nutton RW (2010) What is the role of lateral retinacular release? J Bone Joint Surg Br 92(1):1-6. https://doi. org/10.1302/0301-620X.92B1.22909

35. Sanchis-Alfonso V, Montesinos-Berry E (2015) Is lateral retinacular release still a valid surgical option? From release to lengthening. Ann Transl Med 3(19):301. https://doi.org/10.3978/j. issn.2305-5839.2015.11.15

36. Moher D, Liberati A, Tetzlaff J, Altman DG, Group P (2009) Preferred reporting items for systematic reviews and meta-analyses: the PRISMA statement. BMJ 339:b2535. https://doi.org/10.1136/ bmj.b2535

37. Howick J CI, Glasziou P, Greenhalgh T, Heneghan C, Liberati A, Moschetti I, Phillips B, Thornton H, Goddard O, Hodgkinson M (2011) The 2011 Oxford Levels of Evidence. Oxford Centre for Evidence-Based Medicine, Oxford. https://www.cebmnet/index aspx $? 0=5653$

38. Briggs KK, Lysholm J, Tegner Y, Rodkey WG, Kocher MS, Steadman JR (2009) The reliability, validity, and responsiveness of the Lysholm score and Tegner activity scale for anterior cruciate ligament injuries of the knee: 25 years later. Am J Sports Med 37(5):890-897. https://doi.org/10.1177/036354650833014 3

39. Huang CC, Chen WS, Tsai MW, Wang WT (2017) Comparing the Chinese versions of two knee-specific questionnaires (IKDC and KOOS): reliability, validity, and responsiveness. Health
Qual Life Outcomes 15(1):238. https://doi.org/10.1186/s1295 5-017-0814-6

40. Celik D, Coban O, Kilicoglu O (2019) Minimal clinically important difference of commonly used hip-, knee-, foot-, and anklespecific questionnaires: a systematic review. J Clin Epidemiol 113:44-57. https://doi.org/10.1016/j.jclinepi.2019.04.017

41. Green A, Liles C, Rushton A, Kyte DG (2014) Measurement properties of patient-reported outcome measures (PROMS) in Patellofemoral Pain Syndrome: a systematic review. Man Ther 19(6):517-526. https://doi.org/10.1016/j.math.2014.05.013

42. Collins NJ, Misra D, Felson DT, Crossley KM, Roos EM (2011) Measures of knee function: International Knee Documentation Committee (IKDC) Subjective Knee Evaluation Form, Knee Injury and Osteoarthritis Outcome Score (KOOS), Knee Injury and Osteoarthritis Outcome Score Physical Function Short Form (KOOS-PS), Knee Outcome Survey Activities of Daily Living Scale (KOS-ADL), Lysholm Knee Scoring Scale, Oxford Knee Score (OKS), Western Ontario and McMaster Universities Osteoarthritis Index (WOMAC), Activity Rating Scale (ARS), and Tegner Activity Score (TAS). Arthritis Care Res 63(Suppl 11):S208-228. https://doi.org/10.1002/acr.20632

43. Dzioba RB, Strokon A, Mulbry L (1985) Diagnostic arthroscopy and longitudinal open lateral release: a safe and effective treatment for "chondromalacia patella." Arthroscopy 1(2):131-135

44. Grana WA, Hinkley B, Hollingsworth S (1984) Arthroscopic evaluation and treatment of patellar malalignment. Clin Orthop Relat Res 186:122-128

45. Krompinger WJ, Fulkerson JP (1983) Lateral retinacular release for intractable lateral retinacular pain. Clin Orthop Relat Res 179:191-193

46. Larson RL, Cabaud HE, Slocum DB, James SL, Keenan T, Hutchinson T (1978) The patellar compression syndrome: surgical treatment by lateral retinacular release. Clin Orthop Relat Res 134:158-167

47. Metcalf RW (1982) An arthroscopic method for lateral release of subluxating or dislocating patella. Clin Orthop Relat Res 167:9-18

48. Panni AS, Tartarone M, Patricola A, Paxton EW, Fithian DC (2005) Long-term results of lateral retinacular release. Arthroscopy 21(5):526-531. https://doi.org/10.1016/j.arthr o.2005.01.007

49. Lattermann C, Toth J, Bach BR Jr (2007) The role of lateral retinacular release in the treatment of patellar instability. Sports Med Arthrosc Rev 15(2):57-60. https://doi.org/10.1097/ JSA.0b013e318042af30

50. Unal B, Hinckel BB, Sherman SL, Lattermann C (2017) Comparison of lateral retinaculum release and lengthening in the treatment of patellofemoral disorders. Am J Orthop 46(5):224-228

51. Pagenstert G, Wolf N, Bachmann M, Gravius S, Barg A, Hintermann B, Wirtz DC, Valderrabano V, Leumann AG (2012) Open lateral patellar retinacular lengthening versus open retinacular release in lateral patellar hypercompression syndrome: a prospective double-blinded comparative study on complications and outcome. Arthroscopy 28(6):788-797. https://doi.org/10.1016/j. arthro.2011.11.004

52. Rhatomya SRN, Riky S, Shinta S, Gaold LP, Budipharama NC (2019) Minimal invasive MPFL reconstruction using quadriceps tendon graft with lateral release: 2 years follow up. Int J Surg Open 17:20-26. https://doi.org/10.1016/j.ijso.2019.01.004

53. Malatray M, Magnussen R, Lustig S, Servien E (2019) Lateral retinacular release is not recommended in association to MPFL reconstruction in recurrent patellar dislocation. Knee Surg Sports Traumatol Arthrosc 27(8):2659-2664. https://doi.org/10.1007/ s00167-018-5294-7 
54. Zhang L, Li Z (2019) Long-term clinical results of double bundle reconstruction of the medial patellofemoral ligament for patellar instability. J Knee Surg 32(2):153-159. https://doi. org/10.1055/s-0038-1636913

55. Nomura E, Horiuchi Y, Kihara M (2000) A mid-term followup of medial patellofemoral ligament reconstruction using an artificial ligament for recurrent patellar dislocation. Knee 7(4):211-215

56. Matsushita T, Kuroda R, Oka S, Matsumoto T, Takayama K, Kurosaka M (2014) Clinical outcomes of medial patellofemoral ligament reconstruction in patients with an increased tibial tuberosity-trochlear groove distance. Knee Surg Sports Traumatol Arthrosc 22(10):2438-2444. https://doi.org/10.1007/s0016 7-014-2919-3

57. Watanabe T, Muneta T, Ikeda H, Tateishi T, Sekiya I (2008) Visual analog scale assessment after medial patellofemoral ligament reconstruction: with or without tibial tubercle transfer. J Orthop Sci 13(1):32-38. https://doi.org/10.1007/s00776-007-1196-0

58. Elias DA, White LM, Fithian DC (2002) Acute lateral patellar dislocation at MR imaging: injury patterns of medial patellar soft-tissue restraints and osteochondral injuries of the inferomedial patella. Radiology 225(3):736-743. https://doi.org/10.1148/ radiol.2253011578

59. Guerrero P, Li X, Patel K, Brown M, Busconi B (2009) Medial patellofemoral ligament injury patterns and associated pathology in lateral patella dislocation: an MRI study. Sports Med Arthrosc Rehabil Ther Technol 1(1):17. https://doi. org/10.1186/1758-2555-1-17

60. Vollnberg B, Koehlitz T, Jung T, Scheffler S, Hoburg A, Khandker D, Hamm B, Wiener E, Diederichs G (2012) Prevalence of cartilage lesions and early osteoarthritis in patients with patellar dislocation. Eur Radiol 22(11):2347-2356. https://doi. org/10.1007/s00330-012-2493-3

61. Nomura E, Inoue M, Kurimura M (2003) Chondral and osteochondral injuries associated with acute patellar dislocation. Arthroscopy 19(7):717-721

62. Sanders TG, Paruchuri NB, Zlatkin MB (2006) MRI of osteochondral defects of the lateral femoral condyle: incidence and pattern of injury after transient lateral dislocation of the patella. AJR Am J Roentgenol 187(5):1332-1337. https://doi. org/10.2214/AJR.05.1471

63. von Engelhardt LV, Raddatz M, Bouillon B, Spahn G, David A, Haage P, Lichtinger TK (2010) How reliable is MRI in diagnosing cartilaginous lesions in patients with first and recurrent lateral patellar dislocations? BMC Musculoskelet Disord 11:149. https://doi.org/10.1186/1471-2474-11-149

64. Amin NH, Lynch TS, Patel RM, Patel N, Saluan P (2015) Medial patellofemoral ligament reconstruction. JBJS Rev. https://doi. org/10.2106/JBJS.RVW.N.00089

65. Astur DC, Gouveia GB, Borges JH, Astur N, Arliani GG, Kaleka CC, Cohen M (2015) Medial patellofemoral ligament reconstruction: a longitudinal study comparison of 2 techniques with 2 and 5-years follow-up. Open Orthop J 9:198-203. https://doi. org/10.2174/1874325001509010198

66. Ballal M, Junior Resident PV, Basha N (2018) Functional outcome of Medial patellofemoral ligament injury (MPFL) reconstruction in recurrent patellar dislocation. Int J Orthop Sci 4(4):204-207. https://doi.org/10.22271/ortho.2018.v4.i4d.38

67. Pinheiro Junior LFB, Cenni MHF, Nicolai OP, Gomes LPH, Leal RS, Coelho DGP (2018) Outcomes of medial patellofemoral ligament reconstruction in patients with patella alta. Rev Bras Ortop 53(5):570-574. https://doi.org/10.1016/j.rboe.2017.06.014

68. Bitar AC, D'Elia CO, Demange MK, Viegas AC, Camanho GL (2011) Randomized prospective study on traumatic patellar dislocation: conservative treatment versus reconstruction of the medial patellofemoral ligament using the Patellar Tendon, with a minimum of two years of follow-up. Revista Brasileira de Ortopedia 46(6):675-683. https://doi.org/10.1016/s2255 -4971(15)30324-4

69. Bitar AC, Demange MK, D'Elia CO, Camanho GL (2012) Traumatic patellar dislocation: nonoperative treatment compared with MPFL reconstruction using patellar tendon. Am J Sports Med 40(1):114-122. https://doi.org/10.1177/0363546511423742

70. Calapodopulos CJ, Nogueira MC, Eustaquio JM, Calapodopulos Junior CJ, Rodrigues OA (2016) Reconstruction of the medial patellofemoral ligament using autologous graft from quadriceps tendon to treat recurrent patellar dislocation. Rev Bras Ortop 51(2):187-193. https://doi.org/10.1016/j.rboe.2016.01.012

71. Christiansen SE, Jacobsen BW, Lund B, Lind M (2008) Reconstruction of the medial patellofemoral ligament with gracilis tendon autograft in transverse patellar drill holes. Arthroscopy 24(1):82-87. https://doi.org/10.1016/j.arthro.2007.08.005

72. Csintalan RP, Latt LD, Fornalski S, Raiszadeh K, Inacio MC, Fithian DC (2014) Medial patellofemoral ligament (MPFL) reconstruction for the treatment of patellofemoral instability. $\mathrm{J}$ Knee Surg 27(2):139-146. https://doi.org/10.1055/s-0033-13606 52

73. Deie M, Ochi M, Adachi N, Shibuya H, Nakamae A (2011) Medial patellofemoral ligament reconstruction fixed with a cylindrical bone plug and a grafted semitendinosus tendon at the original femoral site for recurrent patellar dislocation. Am J Sports Med 39(1):140-145. https://doi.org/10.1177/0363546510 377436

74. Feller JA, Richmond AK, Wasiak J (2014) Medial patellofemoral ligament reconstruction as an isolated or combined procedure for recurrent patellar instability. Knee Surg Sports Traumatol Arthrosc 22(10):2470-2476. https://doi.org/10.1007/s0016 7-014-3132-0

75. Fink C, Veselko M, Herbort M, Hoser C (2014) MPFL reconstruction using a quadriceps tendon graft: part 2: operative technique and short term clinical results. Knee 21(6):1175-1179. https://doi.org/10.1016/j.knee.2014.05.006

76. Ellera Gomes JL (1992) Medial patellofemoral ligament reconstruction for recurrent dislocation of the patella: a preliminary report. Arthroscopy 8(3):335-340

77. Ellera Gomes JL, Stigler Marczyk LR, Cesar de Cesar P, Jungblut CF (2004) Medial patellofemoral ligament reconstruction with semitendinosus autograft for chronic patellar instability: a follow-up study. Arthroscopy 20(2):147-151. https://doi. org/10.1016/j.arthro.2003.11.006

78. Gomes JE (2008) Comparison between a static and a dynamic technique for medial patellofemoral ligament reconstruction. Arthroscopy 24(4):430-435. https://doi.org/10.1016/j.arthr o.2007.11.005

79. Gonçaives MBJ, Júnior LHdC, Soares LFM, Gonçaives TJ, dos Santos RL, Pereira ML (2011) Medial patellofemoral ligament reconstruction to treat recurrent patellar dislocation. Revista Brasileira de Ortopedia 46(2):160-164. https://doi.org/10.1016/ s2255-4971(15)30233-0

80. Goyal D (2013) Medial patellofemoral ligament reconstruction: the superficial quad technique. Am J Sports Med 41(5):10221029. https://doi.org/10.1177/0363546513477828

81. Hiemstra LA, Kerslake S, Lafave M (2017b) Medial patellofemoral ligament reconstruction femoral tunnel accuracy: relationship to disease-specific quality of life. Orthop J Sports Med 5(2):2325967116687749. https://doi.org/10.1177/2325967116 687749

82. Hinterwimmer S, Imhoff AB, Minzlaff $P$, Saier T, Rosenstiel N, Hawe W, Feucht MJ (2013) Anatomical two-bundle medial patellofemoral ligament reconstruction with hardware-free patellar graft fixation: technical note and preliminary results. Knee 
Surg Sports Traumatol Arthrosc 21(9):2147-2154. https://doi. org/10.1007/s00167-013-2498-8

83. Howells NR, Barnett AJ, Ahearn N, Ansari A, Eldridge JD (2012) Medial patellofemoral ligament reconstruction: a prospective outcome assessment of a large single centre series. J Bone Joint Surg Br 94(9):1202-1208. https://doi. org/10.1302/0301-620X.94B9.28738

84. Kang H, Cao J, Yu D, Zheng Z, Wang F (2013) Comparison of 2 different techniques for anatomic reconstruction of the medial patellofemoral ligament: a prospective randomized study. Am J Sports Med 41(5):1013-1021. https://doi.org/10.1177/03635 46513480468

85. Kim TS, Kim HJ, Ra IH, Kyung HS (2015) Medial patellofemoral ligament reconstruction for recurrent patellar instability using a gracilis autograft without bone tunnel. Clin Orthop Surg 7(4):457-464. https://doi.org/10.4055/cios.2015.7.4.457

86. Kita K, Tanaka Y, Toritsuka Y, Amano H, Uchida R, Takao R, Horibe S (2015) Factors affecting the outcomes of double-bundle medial patellofemoral ligament reconstruction for recurrent patellar dislocations evaluated by multivariate analysis. Am J Sports Med 43(12):2988-2996. https://doi.org/10.1177/03635 46515606102

87. Krishna Kumar M, Renganathan S, Joseph CJ, Easwar T, Rajan DV (2014) Medial patellofemoral ligament reconstruction in patellar instability. Indian J Orthop 48(5):501-505. https://doi. org/10.4103/0019-5413.139864

88. Lind M, Enderlein D, Nielsen T, Christiansen SE, Fauno P (2016) Clinical outcome after reconstruction of the medial patellofemoral ligament in paediatric patients with recurrent patella instability. Knee Surg Sports Traumatol Arthrosc 24(3):666-671. https://doi.org/10.1007/s00167-014-3439-x

89. Niu J, Qi Q, Fu K, Duan G, Liu C, Wang F (2017) Medial patellofemoral ligament reconstruction with semi-patellar tunnel fixation: surgical technique and mid-term follow-up. Med Sci Monit 23:5870-5875. https://doi.org/10.12659/msm.905583

90. Panni AS, Alam M, Cerciello S, Vasso M, Maffulli N (2011) Medial patellofemoral ligament reconstruction with a divergent patellar transverse 2-tunnel technique. Am J Sports Med 39(12):2647-2655. https://doi.org/10.1177/0363546511420079

91. Ronga M, Oliva F, Longo UG, Testa V, Capasso G, Maffulli N (2009) Isolated medial patellofemoral ligament reconstruction for recurrent patellar dislocation. Am J Sports Med 37(9):17351742. https://doi.org/10.1177/0363546509333482

92. Sadigursky D, de Melo Laranjeira MS, Nunes M, Caneiro RJ, Colavolpe PO (2016) Reconstruction of the medial patellofemoral ligament by means of the anatomical double-bundle technique using metal anchors. Rev Bras Ortop 51(3):290-297. https://doi. org/10.1016/j.rboe.2015.07.011

93. Slenker NR, Tucker BS, Pepe MD, Marchetto PA, Cohen SB (2013) Short-/intermediate-term outcomes after medial patellofemoral ligament reconstruction in the treatment of chronic lateral patellofemoral instability. Phys Sportsmed 41(2):26-33. https://doi.org/10.3810/psm.2013.05.2009

94. Sillanpaa P, Mattila VM, Visuri T, Maenpaa H, Pihlajamaki H (2008) Ligament reconstruction versus distal realignment for patellar dislocation. Clin Orthop Relat Res 466(6):1475-1484. https://doi.org/10.1007/s11999-008-0207-6

95. Smith TO, Mann CJ, Donell ST (2014) Does knee joint proprioception alter following medial patellofemoral ligament reconstruction? Knee 21(1):21-27. https://doi.org/10.1016/j. knee.2012.09.013

96. Thaunat M, Erasmus PJ (2007) The favourable anisometry: an original concept for medial patellofemoral ligament reconstruction. Knee 14(6):424-428. https://doi.org/10.1016/j. knee.2007.08.008

97. Kumahashi N, Kuwata S, Tadenuma T, Kadowaki M, Uchio Y (2012) A "sandwich" method of reconstruction of the medial patellofemoral ligament using a titanium interference screw for patellar instability in skeletally immature patients. Arch Orthop Trauma Surg 132(8):1077-1083. https://doi.org/10.1007/s0040 2-012-1516-5

98. Kumahashi N, Kuwata S, Takuwa H, Egusa N, Uchio Y (2016) Longitudinal change of medial and lateral patellar stiffness after reconstruction of the medial patellofemoral ligament for patients with recurrent patellar dislocation. J Bone Joint Surg Am 98(7):576-583. https://doi.org/10.2106/JBJS.15.00605

99. Rhatomy SSN, Setyawan R, Primasara S, Gaold IL, Budipharama NC (2019) Minimal invasive MPFL reconstruction using quadriceps tendon graft with lateral release: 2 years follow up. Int $\mathbf{J}$ Surg Open 17:20-26. https://doi.org/10.1016/j.ijso.2019.01.004

100. Vavalle G, Capozzi M (2016) Isolated reconstruction of the medial patellofemoral ligament with autologous quadriceps tendon. J Orthop Traumatol 17(2):155-162. https://doi.org/10.1007/ s10195-015-0375-6

101. Wang F, Kang HJ, Chen BC, Chen W, Su YL, Zhang YZ (2010) Combination of medial patellofemoral ligament reconstruction with vastus medialis advancement for chronic patellar dislocation. Chin Med J 123(21):3024-3029

102. Witonski D, Keska R, Synder M, Sibinski M (2013) An isolated medial patellofemoral ligament reconstruction with patellar tendon autograft. Biomed Res Int 2013:637678. https://doi. org/10.1155/2013/637678

Publisher's Note Springer Nature remains neutral with regard to jurisdictional claims in published maps and institutional affiliations. 